Abstract ID: 119

\title{
Effect of Sarang Semut Plant Extract (Myrmecodia Pendens) on wound healing of extracted tooth socket in Sprague Dawley rats
}

\author{
Bo Bo Ko ${ }^{\mathrm{a}} \mid$ Widya Lestari ${ }^{\mathrm{a}} \mid$ Alfi Khatib $^{\mathrm{a}}$ | Haszelini Hassan ${ }^{\mathrm{b}} \mid$ Aung Gyi ${ }^{\mathrm{c}}$ \\ ${ }^{a}$ Kulliyyah of Dentistry, International Islamic University Malaysia \\ ${ }^{b}$ Kulliyyah of Pharmacy, International Islamic University Malaysia \\ ${ }^{`} K u l l i y y a h$ of Medicine, International Islamic University Malaysia
}

Introduction: Sarang semut (Myrmecodia Pendens) is a well-known traditional medication used by indigenous people of Papua for many diseases such as cancer, rheumatism, and ulcers. However, scientific publication of its curative properties is still lacking. This study was designed to investigate the effect of sarang semut extract on the healing process of tooth socket in Sprague Dawley rats. Methods: Thirty six adult male rats were randomly divided into six groups of six animals each. Group 1 served as a control group (no extraction). While Group 2 and 3 served as a negative control and positive control respectively. Immediately after the extraction of the right lower first molar tooth, the alveolar socket was treated with $1.5 \%$ sarang semut paste (SSP) (Group 4), 3\% SSP (Group 5) and 5\% SSP (Group 6). Two rats from each group were sacrificed at day 4,7 and 18 consecutively. The extracted tooth socket was sectioned and stained with H\&E stains. Soft tissue healing score of $\geq 16$ indicates good healing has occurred. Whereas new bone formation of grade 2 and 3 indicates a fair and good percentage of newly deposited bone formation, respectively. Results: Histological analysis showed that soft tissue healing score for 3\% SSP groups was highest (mean=19) when compared to all groups at day 18 after tooth extraction. All groups showed a good increase in the amount of bone trabeculae formed with mean grade of 2. Conclusions: This finding suggests that 3\% SSP has a promising therapeutic effect on soft tissue intraoral wound healing.

KEYWORDS: Socket healing, Sarang Semut extract 